\title{
THE MEASUREMENT OF BLOOD FLOW BY THE LOCAL CLEARANCE OF RADIOACTIVE SODIUM
}

\author{
BY \\ H. MILLER and G. M. WILSON \\ From the Sheffield National Centre for Radiotherapy and the Department of Pharmacology and Therapeutics, University \\ of Sheffield
}

Received October 7, 1950

The study of the local clearance of radioactive sodium was initiated by Kety (1948) who suggested that the rate of loss of local radioactivity reflected the local effective blood flow. The method has, up to date, been used for the study of blood flow in muscle (Kety, 1949; Cooper et al., 1949 and Cooper, 1949) and it was shown that after application of a tourniquet to check the arterial inflow the number of counts per minute remained constant. On release of the tourniquet there was a rapid decline in the counts per minute attributed to the reactive hyperæmia. As the counts thus apparently reflected both the cessation of the circulation while the tourniquet was applied and the subsequent increase on its release, the method was thought suitable for the relative determination of effective local blood flow and useful for studying the circulation in particular in the skin and viscera (Kety, 1949). Obviously such a method would be convenient and simple for the investigation of circulation in organs otherwise inaccessible for circulatory studies. Before such extensive use it is, however, essential to ascertain that the method is capable of determining with reasonable accuracy changes in effective local blood flow. Experiments involving the use of a tourniquet on a limb were not considered sufficient evidence for this assumption, and further investigations on the local clearance of radiosodium in skin and muscle are accordingly presented.

\section{METHOD}

The procedure is essentially that described by Kety (1949). The $\mathrm{Na}_{24}$ was prepared in isotonic sodium chloride solution. In the investigation of the skin the injection contained between 2 and 3 microcuries of $\mathrm{Na}_{24}$ and was adjusted by dilution with isotonic saline to a volume of between 0.05 and $0.15 \mathrm{ml}$. This was injected either intradermally to raise a wheal or slightly deeper into the cutaneous tissue. A slight leak back of fluid and blood along the needle track might occur and it was important to wash this off and not to place the Geiger-Muller counter in position until the aperture in the skin had sealed. In the investigation of muscle the depot was placed at $2 \mathrm{~cm}$. depth and accordingly the activity of the solution was increased to about 5 microcuries and the volume to between $0.2 \mathrm{ml}$. and $0.5 \mathrm{ml}$. Counts were recorded over periods of 30 seconds at minute intervals and the results have either been plotted semilogarithmically or expressed as the clearance constant as defined by Kety (1949). This constant is proportional to the rate of disappearance of the radiosodium from the depot.

To ascertain the changes in the skin circulation the heat elimination of the hand was measured in a calorimeter of the improved pattern described by Greenfield and Scarborough (1949). The injection of radiosodium was made either into the opposite hand and the counter placed in contact with the skin or into the hand inserted in the calorimeter. In the latter case the counting was carried out through the wall of the vacuum flask; this ensured that the calorimetric and radiosodium measurements were made under identical local conditions though the hand could not be held so 
steady as when supported outside on a sandbag. Alterations in skin blood flow were produced by immersing either the feet or the free upper limb in water at $44^{\circ}$ and $15^{\circ} \mathrm{C}$. Variations in skeletal muscular blood flow were brought about by the intravenous infusion of synthetically prepared lævo-adrenaline in a dose varying from 5 to $30 \mu \mathrm{g}$. a minute. Before the observations were begun a saline drip was established and through a $\mathrm{Y}$ connection either normal saline or saline containing adrenaline was infused.

\section{RESULTS}

In investigating the cutaneous circulation, the depot of radiosodium was placed in the dorsum of either the hand in the region of the knuckles or the middle or distal phalanx of the middle finger. In the first instance, the clearance rates were studied at room temperature $\left(19^{\circ}-22^{\circ} \mathrm{C}\right)$ and in response to indirect heating and cooling. Little alteration was noted in the clearance constant though it was considered that these procedures were sufficient to cause large alterations in cutaneous blood flow. These results were accordingly compared with simultaneous observations made with the calorimeter.

TABLE I

Comparison of Heat Elimination and local Clearance of Radiosodium in the Hand

\begin{tabular}{c|c|c|c|c|c|c}
\hline \multirow{2}{*}{$\begin{array}{c}\text { Experiment } \\
\text { No. }\end{array}$} & \multicolumn{2}{|c|}{ Preliminary } & \multicolumn{2}{c|}{ Full reflex vasodilatation } & \multicolumn{2}{c}{ Reflex vasoconstriction } \\
\cline { 2 - 5 } & $\begin{array}{c}\text { Heat } \\
\text { elimination } \\
\text { cal./min. }\end{array}$ & $\begin{array}{c}\text { Clearance } \\
\text { constant }\end{array}$ & $\begin{array}{c}\text { Heat } \\
\text { elimination } \\
\text { cal./min. }\end{array}$ & $\begin{array}{c}\text { Clearance } \\
\text { constant }\end{array}$ & $\begin{array}{c}\text { Heat } \\
\text { elimination } \\
\text { cal./min. }\end{array}$ & $\begin{array}{c}\text { Clearance } \\
\text { constant }\end{array}$ \\
\hline 1 & 103 & 0.021 & 332 & 0.025 & 95 & 0.018 \\
\hline 2 & 164 & 0.030 & 290 & 0.023 & 81 & 0.030 \\
\hline 3 & 244 & 0.051 & 300 & 0.039 & 217 & 0.023 \\
\hline 4 & 110 & 0.067 & 333 & 0.064 & 82 & 0.035 \\
\hline
\end{tabular}

The results in all the experiments involving skin blood flow are shown in Table I. Fig. 1 shows the changes in heat elimination in one hand and in radiosodium counts in the other hand when the feet were placed in hot and cold water. Fig. 2 illustrates an experiment in which the calorimetric observations and radiosodium counts were made in the same hand. In all the observations the results were similar. During the initial period a steady local clearance of radiosodium was observed and we confirmed that this clearance could be completely checked by inflating a cuff round the upper limb above systolic pressure. Little change in the rate of local clearance of. $\mathrm{Na}_{24}$ was observed when full reflex vasodilatation had been produced by the indirect heating. Though the heat elimination might be increased threefold or more, the clearance constant showed only a slight, or no increase. Reflex vasoconstriction produced by cold water led to an immediate reduction in the heat elimination and to a decrease in the clearance constant. These findings were constant irrespective of the site or depth of the radiosodium injection in the hand or finger.

In resting muscle, clearance constants similar to those reported by other workers have been obtained. The results are shown in Table II. The clearance was stopped by a cuff inflated above the arterial pressure and release of the pressure was followed by a period of removal of the radiosodium at a higher rate (Fig. 4). Intravenous infusion of adrenaline in doses up to $30 \mu \mathrm{g}$. a minute in six experiments (Table II) produced only a slight increase or no significant change in the clearance constant (Fig. 3 and 4). The adrenaline used was shown to be active by the development of marked pallor of the face and palpitations, and by the characteristic changes in the pulse rate and blood pressure. 


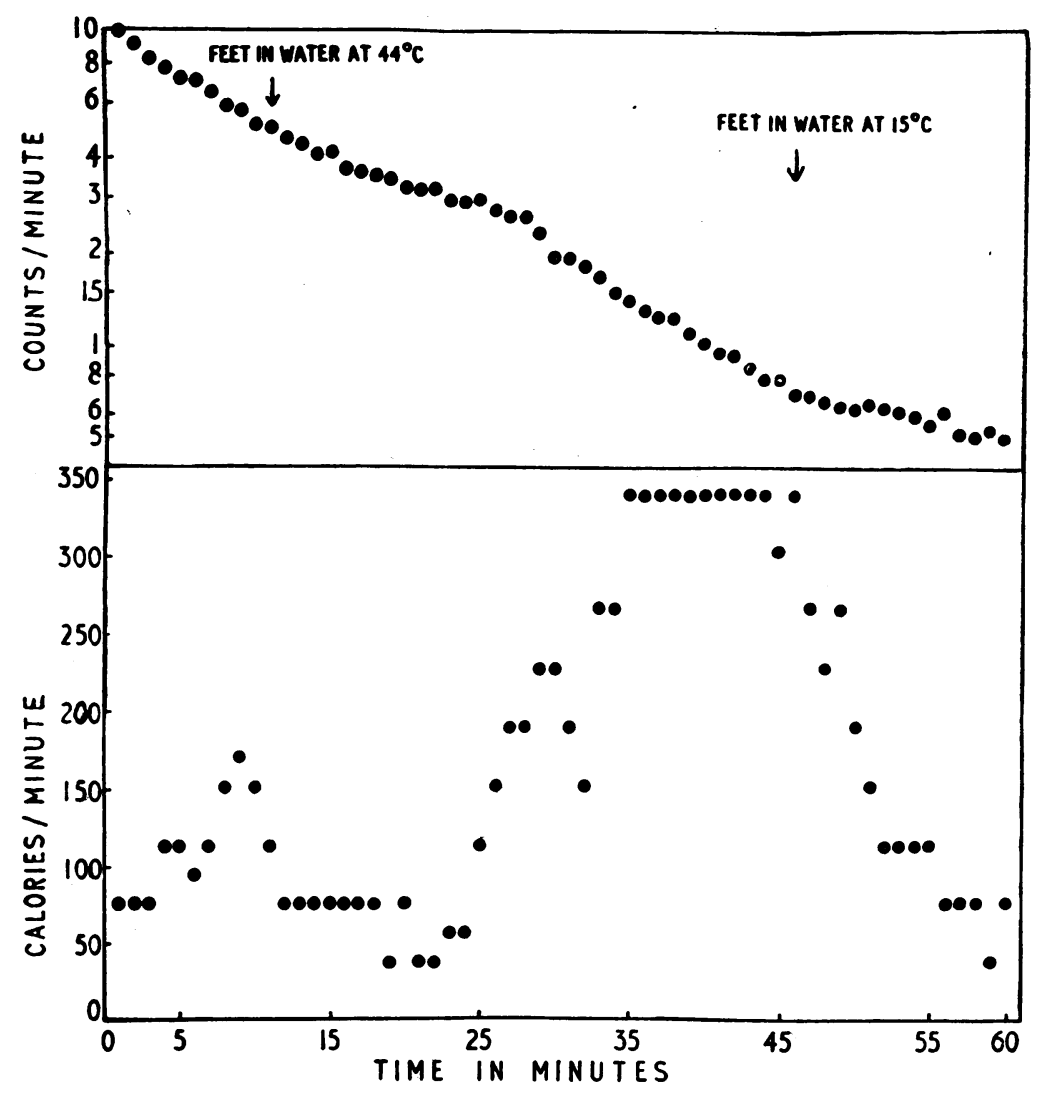

Fig. 1.- Simultaneous measurement of the clearance of a depot of radiosodium in the skin of the dorsum of the left middle finger and of the heat elimination from the right hand. At the points marked the feet were placed in hot and cold water. The considerable changes in heat elimination were not associated with any conspicuous corresponding changes in radiosodium clearance.

TABLE II

The EfFect of Intravenous Adrenaline INfusions on the Clearance of Radiosodium in Muscle

\begin{tabular}{c|c|c|c}
\hline $\begin{array}{c}\text { Experiment } \\
\text { No. }\end{array}$ & Saline infusion & \multicolumn{2}{|c}{ L-Adrenaline infusion } \\
\cline { 2 - 4 } \cline { 2 - 3 } & Clearance constant & $\begin{array}{c}\text { Dose } \\
\mu \mathrm{g} . / \mathrm{min} .\end{array}$ & Clearance constant \\
\hline 5 & 0.051 & 5 & 0.048 \\
\hline 6 & 0.053 & 15 & 0.041 \\
\hline 7 & 0.048 & 20 & 0.057 \\
\hline 8 & 0.133 & 20 & 0.140 \\
\hline 9 & 0.041 & 25 & 0.055 \\
\hline 10 & 0.064 & 30 & 0.060 \\
\hline
\end{tabular}




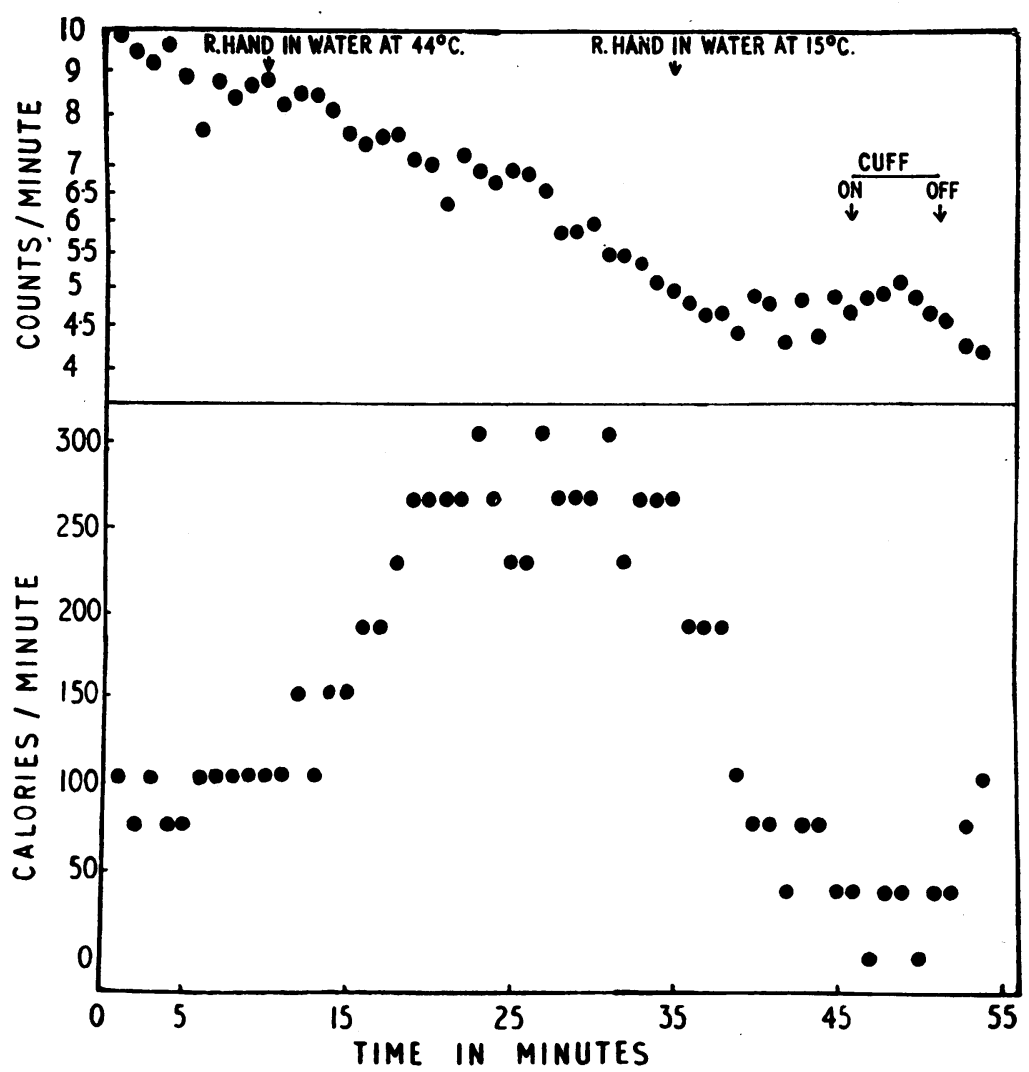

Fig. 2.-Simultaneous measurement of the local clearance of a depot of radiosodium in the skin of the left middle finger and of the heat elimination from the left hand. The circulatory changes resulting from placing the right hand in hot and cold water and from inflation of a cuff on the left arm are shown.

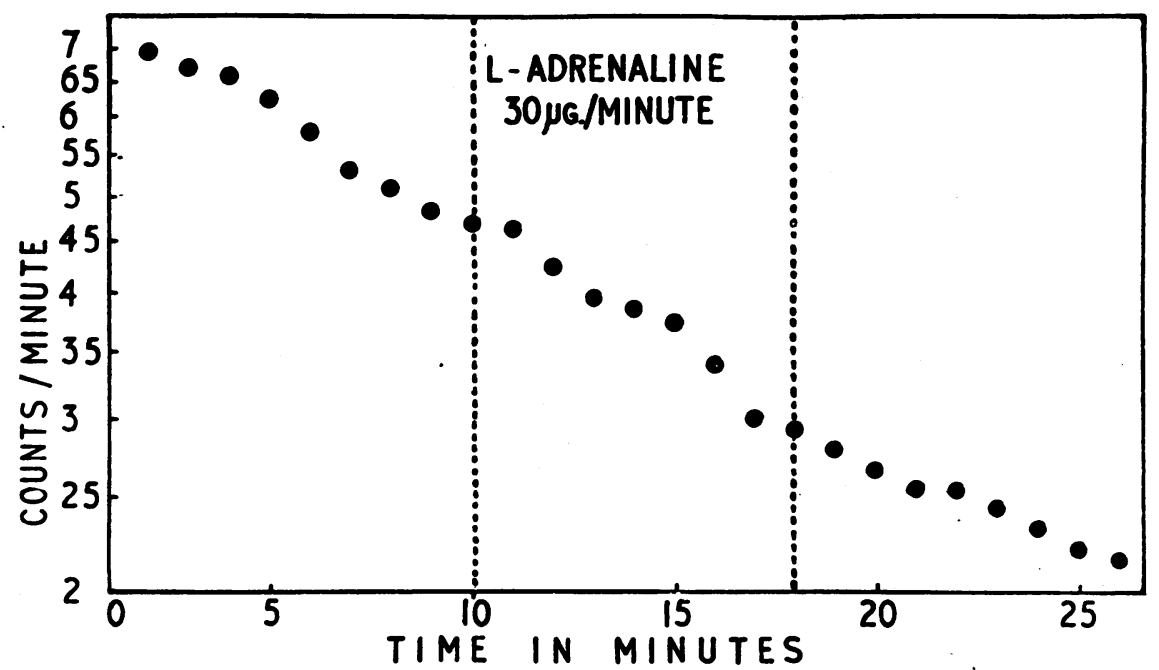

Fig. 3.-Local clearance of a depot of radiosodium in the calf muscle. The intravenous infusion of adrenaline at a high rate did not appreciably increase the rate of removal of the radiosodium. 


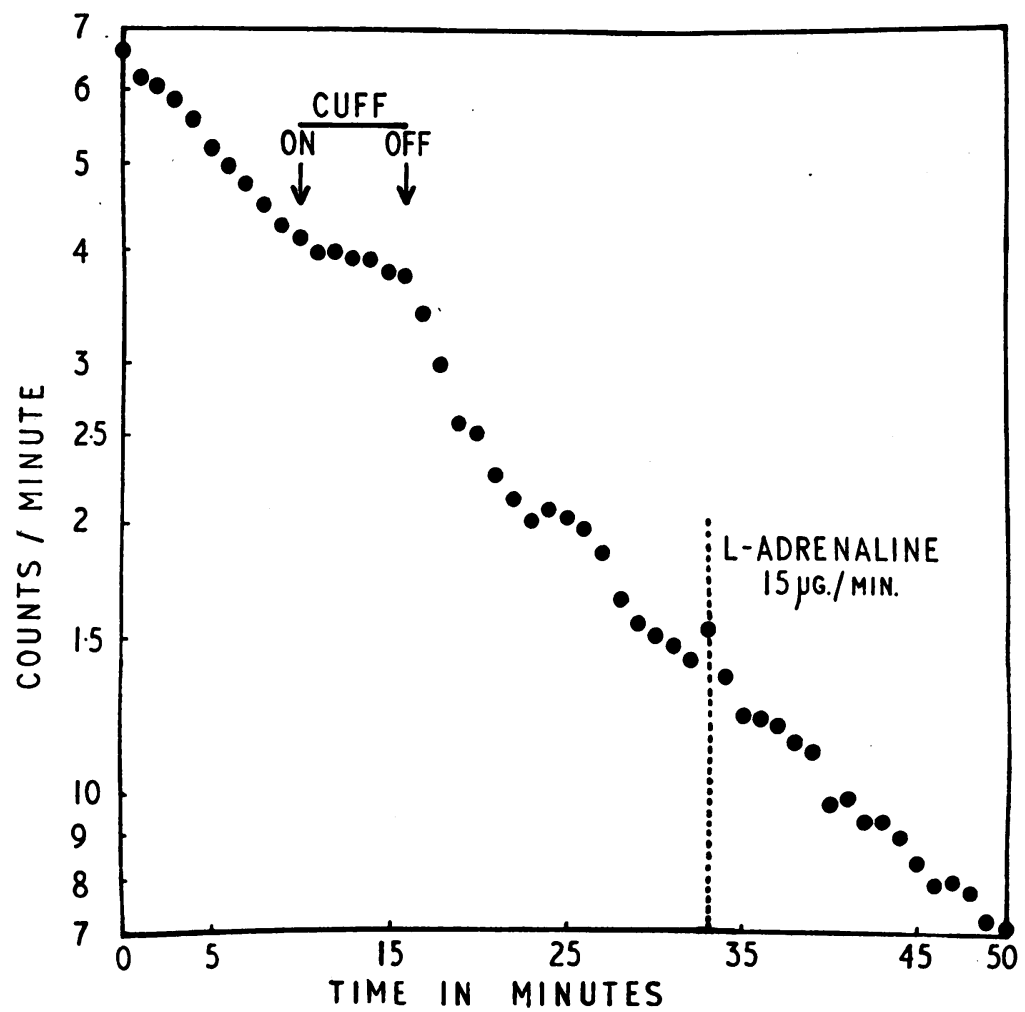

FIG. 4.-Local clearance of a depot of radiosodium in the forearm muscle showing the effect of inflation of a cuff on the arm and of an intravenous infusion of adrenaline. The removal of radiosodium is checked by the tourniquet but not increased by intravenous adrenaline.

\section{Discussion}

The local clearance of radiosodium depends on many factors which have been enumerated by Kety (1949). Removal by lymphatics is probably negligible and if this quantity is disregarded and local diffusion in the tissue planes is slight, the clearance is determined by the rate at which the radiosodium is removed in the blood vessels. This must depend on the rate of exchange of sodium between the depot and the plasma within the capillaries and the number of patent functioning capillaries in the vicinity of the depot. The velocity and volume of flow in patent capillaries can only be of importance in so far as they expedite the transfer of radiosodium from the depot to the vessels.

In the skin the failure of the clearance constant to increase during a period of reflex vasodilatation may be due to the blood passing through arteriovenous anastomoses and thus being ineffective as far as tissue exchanges are concerned. It should, however, be noted that reflex vasoconstriction was associated with a decrease in the clearance constant. This decrease was immediate and thus not secondary to cooling of the part and consequent reduction in local metabolism. Furthermore, the prompt reduction was also observed when the counting was done on the hand in the calorimeter and any local cooling could thus be excluded. Our results thus suggest that the clearance of radiosodium in skin is not solely a measure of effective circulation as determined by local tissue metabolism. It is reduced by reflex vasoconstriction but little affected by reflex vasodilatation. 
The method was no more satisfactory as a means of studying variations in blood flow to skeletal muscle. Intravenous infusion of adrenaline is known to produce a conspicuous vasodilatation in skeletal muscle, and at the onset of the infusion there is an enormous transitory increase in the blood flow; thereafter the blood flow falls slightly but is maintained at a rate considerably above the resting level (Allen et al., 1946). These features were not closely reflected in the clearance rates of radiosodium which were only slightly increased or unaffected by the adrenaline infusions. These changes were within the experimental error of the measurements. The vasodilatation caused by adrenaline is associated with a reduction in the muscle glycogen content and a rise in the blood sugar level (Hildes et al., 1949). This transfer of carbohydrate indicates that an active exchange between muscle and blood stream is taking place; a greatly increased clearance of the radiosodium depot would have been anticipated if the method were measuring accurately muscle blood flow. In the tourniquet experiments during the period of cessation of the arterial circulation, radiosodium is presumably accumulating in the local capillaries and on return of the circulation this unduly high concentration is swept away. The increased clearance rate immediately after a period of ischæmia is thus not sufficient evidence that the clearance of a depot of radiosodium reflects closely blood flow to the tissues under different circumstances.

We thus see that the method, though convenient and easy to use, is relatively insensitive when checked by other methods that are known to measure more accurately alterations in blood flow. It is very doubtful if it is sufficiently sensitive to give information of value regarding blood flow in pathological states of the limbs or in deeper organs where no alternative method is available for comparison.

\section{SUMMARY}

The local clearance of radiosodium injected into skin and muscle has been studied. The observations that application of an arterial tourniquet checked the removal of the radiosodium and that release of the tourniquet was followed by a period of increased rate of clearance were confirmed.

The rate of removal of radiosodium injected into the skin of the hand was not increased by vasodilatation produced by indirect heating but was diminished by reflex vasoconstriction.

Intravenous infusion of lævo-adrenaline produced no significant alteration in the rate of clearance of radiosodium injected into skeletal muscle. The clearance rate in these circumstances did not reflect closely the changes in local blood flow to the muscle.

We wish to thank Professor E. J. Wayne for his helpful criticism and encouragement; and Miss L. Fearn for technical assistance with the counting equipment.

\section{REFERENCES}

Allen, W. J., Barcroft, H., and Edholm, O. G. (1946). J. Physiol., 105, 255. Cooper, F. E. (1949). South Med. J., 42, 870.

Cooper, F. W., Elkin, D. C., Shea, P. C., and Dennis, E. W. (1948). Surg. Gynec. Obstet., 87, 1. Greenfield, A. D. M., and Scarborough, H. (1949). Clin. Sci., 8, 211.

Hildes, J. A., Sherlock, S., and Walshe, V. (1949). I Ibid., 7, 297.

Kety, S. S. (1948). Amer. J. med. Sci., 215, 352.

(1949). Amer. Heart J., 38 ,321. 